\title{
PRINCIPAIS CLASSES DE SOLOS DO MUNICÍPIO DE PRESIDENTE PRUDENTE-SP: IDENTIFICAÇÃO E CARACTERIZAÇÃO*
}

\author{
MAJOR SOIL CLASSES FROM PRESIDENTE PRUDENTE' COUNTY: \\ IDENTIFICATION AND CHARACTERIZATION
}

\author{
PRINCIPALES CLASES DE SUELOS DEL MUNICIPIO DE PRESIDENTE \\ PRUDENTE-SP: INDENTIFICACIÓN Y CARACTERIZACIÓN \\ Melina Fushimi - Universidade Estadual Paulista - São Paulo - São Paulo - Brasil \\ melinafushimi@yahoo.com.br
}

João Osvaldo Rodrigues Nunes - Universidade Estadual Paulista - São Paulo - São Paulo - Brasil joaosvaldo@fct.unesp.br

\begin{abstract}
Resumo
0 presente trabalho teve como objetivo caracterizar os principais aspectos pedológicos do município de Presidente Prudente, localizado no Extremo Oeste do Estado de São Paulo, relacionando-os com o uso da terra, com os compartimentos de relevo (topos, vertentes e fundos de vales) e suas morfologias (vertentes côncavas, convexas e retilíneas e fundos de vales em berço e em "V"). A caracterização dos solos da área de estudo seguiu o traçado de três perfis topográficos - 1, 2 e 3 -, elaborados na direção Oeste-Leste e em campo foram identificados Latossolos, Argissolos, Neossolos, Planossolos e Gleissolos, descritos em três pontos representativos de observação.
\end{abstract}

Palavras-chave: solos, relevo, Presidente Prudente.

\begin{abstract}
The objective of this work was characterize the main pedological aspects in Presidente Prudente's county, located in Extreme West of São Paulo Estate, relating them with land use, with compartments of relief (tops, slopes and funds valley) and their morphologies (concaves, convexes and rectilinear slopes and flat and in "V" funds valley). The soils characterization in study area followed three topographical profiles - 1, 2 e 3 -, elaborated in West-East direction and in field were identified Latosols, Argisols, Neossolos, Planosols and Gleysols, described in three representative points of observation.

Key words: soils, relief, Presidente Prudente.

\section{Resumen}

El presente trabajo tuvo como objectivo caracterizar los principales aspectos pedológicos del municipio de Presidente Prudente, localizado en Extremo Oeste del Estado de São Paulo, relacionándolos con el uso de la tierra, los compartimientos del relieve (tope, pendiente e fondo de valle) y sus morfologias (pendientes cóncavas, convexas e rectilíneas e fondos de valle en cuna y en "V"). La caracterización de los suelos de la área de estudio seguió el trazo de tres perfis topográficos - 1, 2 e 3 -, elaborados en la dirección Oeste-Este y en campo fueron identificados Latossolos, Argissolos, Neossolos, Planossolos e Gleissolos, descritos en tres puntos representativos de observación.
\end{abstract}

Palabras clave: suelos, relieve, Presidente Prudente.

\footnotetext{
*Pesquisa financiada pela FAPESP (Fundação de Amparo à Pesquisa do Estado de São Paulo) e pelo CNPq, edital Universal/2007.
} 
Introdução

Os solos foram, durante muito tempo, estudados como uma subdivisão da Geologia. Atualmente, as pesquisas sobre o tema são interpretadas por várias outras áreas do conhecimento, tais como Química, Agronomia, Arquitetura, História, Engenharia, especialmente a Geografia.

Com base no ponto de vista da Pedologia $($ pedon $=$ solo $+\operatorname{logia}=$ estudo), solo "[...] é a coleção de corpos naturais dinâmicos, que contém matéria viva, e é resultante da ação do clima e da biosfera sobre a rocha, cuja transformação em solo se realiza durante certo tempo e é influenciada pelo tipo de relevo" (Lepsch, 2002, p. 9-10).

Dentre os fatores de formação dos solos, destaca-se a importância do relevo, pois parte da água advinda através da precipitação escoa para terrenos a jusante, modificando o perfil pedológico. A topografia também influencia no grau de remoção de partículas pela erosão, além de facilitar a movimentação de material em suspensão ou em solução para outras áreas.

Dessa forma, o presente artigo pretende caracterizar os principais aspectos pedológicos do município de Presidente Prudente-SP, acompanhando três perfis topográficos elaborados na direção Oeste-Leste e três pontos representativos de observação, relacionando-os com o uso da terra, com os compartimentos de relevo (topos, vertentes e fundos de vales) e suas morfologias (vertentes côncavas, convexas e retilíneas e fundos de vales em berço e em "V").

O município de Presidente Prudente está localizado no Extremo Oeste do Estado de São Paulo e é sede da $10^{\text {a }}$ Região Administrativa. Possui área territorial de $563 \mathrm{~km}^{2}$ e sua população é de 207.625 habitantes, sendo 4.255 rural e 203.370 urbana, de acordo com o Instituto Brasileiro de Geografia e Estatística (IBGE, 2010). É composto, além do perímetro urbano de Presidente Prudente, por quatro Distritos urbanos: Montalvão, Floresta do Sul, Eneida e Ameliópolis. O recorte de estudo limitou-se à área rural do município (Figura 1).

Para a realização de tal intento, este trabalho foi dividido em procedimentos metodológicos; panorama geral da geomorfologia e dos solos do Oeste Paulista, na região de Presidente Prudente; caracterização pedológica (com três pontos de observação) seguindo os perfis topográficos traça- 
dos no município, próximos aos Distritos urbanos de Montalvão, Eneida e Ameliópolis (Figura 1) e, por fim, as considerações finais.

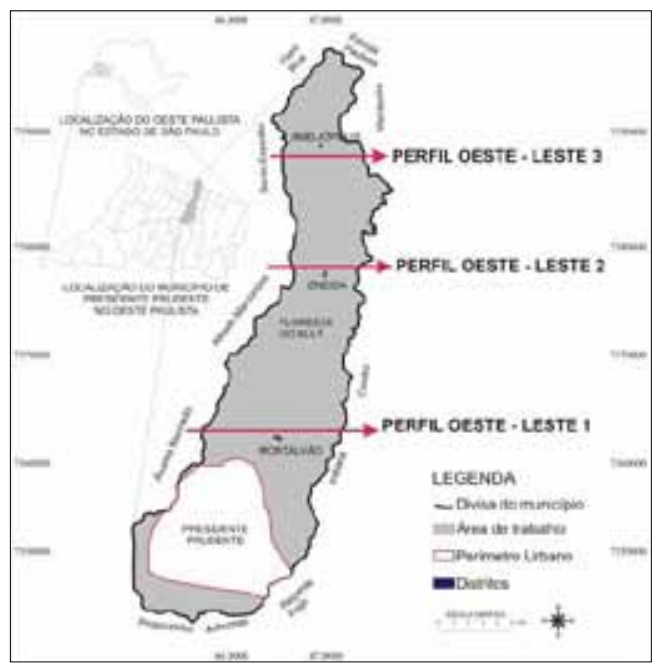

Figura 1 - Localização da área de trabalho e dos perfis topográficos

Procedimentos metodológicos

Os três perfis topográficos foram elaborados no SPRING 4.1 (Sistema de Processamento de Informações Georreferenciadas), ${ }^{1}$ isto é, um software de banco de dados geográfico desenvolvido pelo INPE (Instituto Nacional de Pesquisas Espaciais). Para tal, utilizou-se a base digital planoaltimétrica georreferenciada. Posteriormente, os perfis foram exportados para o programa CorelDRAW X4 $4^{2}$ para a edição gráfica.

Houve trabalhos de campo em que amostras de solos foram coletadas para análises texturais, segundo o Manual de Métodos de Análise de Solos (Embrapa, 1997), utilizando o método da pipeta. Por fim, foram levantados pontos de observação, localizando as coordenadas geográficas e a elevação com o auxílio de um GPS (Global Positioning System). As pesquisas em campo foram essenciais na atualização e no levantamento de dados não obtidos por meio do trabalho de gabinete, especialmente no que se refere ao uso da terra. 


\section{Aspectos geomorfológicos da região de Presidente Prudente-SP}

A primeira divisão do relevo do Estado de São Paulo foi realizada pelo geólogo Luis Flores de Moraes Rego (1932), em que se definiu o Planalto Ocidental, a Depressão Periférica, os relevos cuestiformes e o relevo das áreas cristalinas.

A respeito do relevo do Estado de São Paulo, Ab’Saber, afirma que

os planaltos ocidentais rebaixados do Oeste de São Paulo se constituem em um dos mais notáveis compartimentos rebaixados do conjunto geral do Brasil Meridional [...] confinando-se ao Norte pelos altiplanos cretácicos do Triângulo Mineiro e, ao S e SW, pelos planaltos arenítico-basálticos e areníticos do Norte do Paraná. (Ab’Saber, 1969, p. 2)

Além disso, apesar da homogeneidade da área,

em vários setores dos “espigões” dos chapadões ocidentais paulistas, mesmo em setores de grande rebaixamento topográfico, existem relevo que escaparam aos efeitos homogenizantes das aplainações neogênicas. (p. 4)

O Mapa Geomorfológico do Estado de São Paulo, elaborado por Ross e Moroz (1996) na escala 1:500.000, com os conceitos de morfoestrutura e morfoescultura, relacionados aos aspectos morfoclimáticos atuais, classifica o relevo em três unidades morfoestruturais: Cinturão Orogênico do Atlântico, Bacia Sedimentar do Paraná e Bacias Sedimentares Cenozoicas. Para cada unidade morfoestrutural têm-se várias unidades morfoesculturais associadas às formas de relevo.

O município de Presidente Prudente está localizado na Bacia Sedimentar do Paraná (morfoestrutura) e no Planalto Ocidental Paulista (morfoescultura), mais precisamente no Planalto Centro Ocidental (Ross e Moroz, 1996, p. 50). As formas de relevo predominantes são as colinas amplas e baixas com altimetria em torno de 300 a 600 metros, declividades que variam entre 10 a $20 \%$ e o predomínio de Latossolos e Argissolos.

\section{Aspectos pedológicos da região de Presidente Prudente-SP}

O primeiro levantamento realmente pedológico efetuado em relação ao Estado de São Paulo foi realizado em 1960, pela antiga Comissão de Solos, 
do Ministério da Agricultura, atualmente, Centro Nacional de Pesquisa de Solos - Embrapa. Adquirindo informações mais confiáveis por meio da progressão dos conhecimentos de pedologia, do aperfeiçoamento de técnicas de prospecção e da existência de mapas base mais precisos e atualizados, além de fotos aéreas, o referido mapa encontra-se desatualizado.

De acordo com o Mapa Pedológico do Estado de São Paulo (Embrapa, 1999), no Oeste Paulista, foram identificados e mapeados oito tipos de solos: os Argissolos Vermelho-Amarelos (PVA); os Argissolos Vermelhos (PV); os Latossolos Vermelhos (LV); os Nitossolos Vermelhos (NV); os Gleissolos Háplicos (GX); os Neossolos Quartzarênicos (RQ); os Neossolos Flúvicos (RU) e os Neossolos Litólicos (RL). Os mais representativos na região de Presidente Prudente são os Argissolos Vermelhos e os Latossolos Vermelhos, resultados de processos pedogenéticos ocorridos em rochas areníticas do Grupo Bauru (Formações Caiuá, Santo Anastácio, Adamantina e Marília) e basálticas do Grupo São Bento (Formação Serra Geral).

Os Latossolos são "solos constituídos por material mineral, apresentando horizonte B latossólico imediatamente abaixo de qualquer tipo de horizonte A, dentro de $200 \mathrm{~cm}$ da superfície do solo ou dentro de $300 \mathrm{~cm}$, se o horizonte A apresenta mais que 150cm de espessura" (Embrapa, 1999, p. 197).

A classe dos Latossolos ocupa cerca de $52 \%$ da área estadual paulista (Brasil, 1960 apud Oliveira, 1999, p. 51), constituindo o agrupamento mais extenso do Estado. Os Latossolos apresentam boas propriedades físicas em avançado estágio de intemperização, cujos perfis são espessos (com mais de três metros de profundidade) e os horizontes bem formados. Em virtude do intenso intemperismo a que são submetidos, em geral são pobres em nutrientes vegetais.

Em Presidente Prudente, localizam-se predominantemente em relevos suavemente ondulados a ondulados, dificultando o desenvolvimento de processos erosivos. Nos suavemente ondulados, os topos são achatados, com vertentes convexas pouco íngremes, variando entre 2 a 5\%. Já nos relevos ondulados, os topos são arredondados, com vertentes convexas, cujas declividades variam entre 5 a 15\%. Os Latossolos apresentam excepcional porosidade, sendo comuns valores de 50 a $60 \%$ e, consequentemente, boa drenagem interna, mesmo nos de textura argilosa. A remoção de grande parte da sílica coloidal torna o solo friável (permitindo que seja facilmente preparado para o cultivo), permeável e não plástico. 
Posterior aos Latossolos, os Argissolos constituem a classe de solo de maior expressão espacial no Estado de São Paulo, ocupando 29\% de sua área (Oliveira, 1999, p. 10).

De acordo com a Embrapa, os Argissolos são

solos constituídos por material mineral, apresentando horizonte B textural com argila de atividade baixa imediatamente abaixo do horizonte A ou E, e satisfazendo, ainda, os seguintes requisitos:

- horizonte plíntico, se presente, não está acima e nem é coincidente com a parte superior do horizonte B textural;

- horizonte glei, se presente, não está acima e nem é coincidente com a parte superior do horiozonte B textural. (Embrapa, 1999, p. 129)

Esses solos apresentam grandes variações no que se refere a características morfológicas e analíticas, porém com presença distintiva de horizonte B textural que diverge do horizonte superficial A ou horizonte $\mathrm{E}$ (onde ocorre perda de materiais, translocados para o horizonte B), seja pela cor, pela diferença de textura e pela complementação marcante de estrutura em blocos, sendo a textura argilosa ou muito argilosa.

Eles estão associados a relevos suavemente ondulados a ondulados. Os primeiros possuem formatos de colinas com rampas de declives longos e topos levemente arredondados ou achatados, com a morfologia dos vales apresentando fundo côncavo.

Os relevos ondulados apresentam-se em forma de colinas de topos também levemente arredondados, com vales mais fechados em "V". Não apresentam qualquer impedimento físico à penetração do sistema radicular, pelo menos, até $200 \mathrm{~cm}$ de profundidade, a não ser que ocorra o fenômeno da compactação, resultante do seu uso inadequado. Além disso, por apresentarem, em geral, textura média ou arenosa em superfície e baixa atividade da fração argila, são facilmente preparados para o plantio (Oliveira, 1999, p. 11).

De modo geral, os Argissolos são susceptíveis à erosão por apresentarem gradiente textural entre o horizonte A ou E e o horizonte B. Esses solos, especialmente quando apresentam mudança textural abrupta, possuem baixa ou muito baixa resistência à erosão (Lombardi Neto et al., 1991 apud Oliveira et al., 1999, p. 11). Tal característica exige práticas conservacionistas de suporte (como curvas de nível e terraceamento). 
Caracterização dos solos do município de Presidente Prudente-SP

A caracterização pedológica do município de Presidente Prudente seguiu o traçado de três perfis topográficos na direção Oeste-Leste, dada a extensão da área de estudo. Em campo, foram identificados Latossolos, Argissolos, Neossolos, Planossolos e Gleissolos, descritos em três pontos representativos de observação.

Ao percorrer o perfil topográfico Oeste-Leste 1 (Figura 2), em determinados locais, o relevo apresenta-se mais acidentado, com colinas pouco amplas e fundos de vale em "V". Esse fato está associado à maior concentração de carbonato de cálcio na Formação Adamantina. Áreas de topos com solos rasos também estão relacionadas com a presença do agente cimentante predominante. A cobertura vegetal original foi substituída por gramínea e o uso da terra é composto pela pastagem, com a ocorrência de queimadas esporádicas, cujos vestígios encontram-se nos horizontes sub e superficiais do solo.

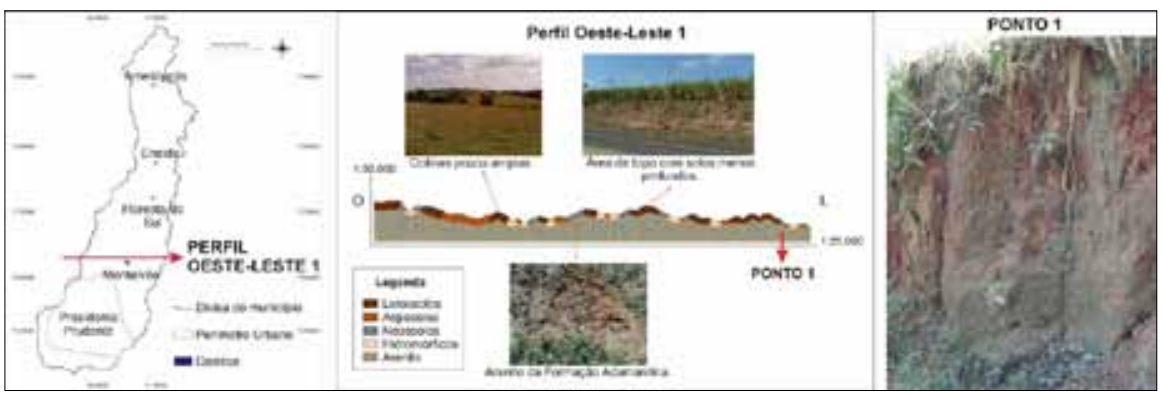

Figura 2 - Localização do perfil topográfico Oeste-Leste 1 e do Ponto 1 e perfil de Neossolo Regolítico

Ponto 1: Próximo ao Distrito de Montalvão, em direção ao Ribeirão do Mandaguari, foram identificados setores com a predominância de Neossolos Regolíticos (Figura 2), isto é, "solos pouco evoluídos e sem horizonte B diagnóstico” (Embrapa, 1999, p. 225). Foi encontrado um horizonte Ap (alterado pela ação antrópica) e posteriormente um horizonte C, que geralmente corresponde ao saprolito, isto é, o arenito pouco alterado pelos processos intempéricos responsáveis pela formação dos solos. Por- 
tanto, a análise textural dos horizontes não foi realizada, somente sua descrição geral (Tabela 1).

Tabela 1 - Descrição Geral do perfil de Neossolo Regolítico

\begin{tabular}{l|l}
\hline Data: & $25 / 4 / 2009$ \\
\hline Identificação: & Neossolo Regolítico \\
\hline Localização, Município, Estado e & $\begin{array}{l}\text { Próximo ao Distrito de Montalvão, Presidente } \\
\text { Prudente, São Paulo, } 22^{\circ} 03^{\prime} 54,0^{\prime \prime} \text { e e } 51^{\circ} 20^{\prime} 42,1^{\prime \prime} \mathrm{W}\end{array}$ \\
\hline Coordenadas: & Média vertente com declividades entre 10 a $20 \%$ \\
\hline Coberacão e declividade: & Floresta Tropical Subperenifólia e gramínea \\
\hline Altitude: & $420 \mathrm{~m}$ \\
\hline Litologia e Formação Grimária e atual: Geógica: & Arenito da Formação Adamantina \\
\hline Cronologia: & Cretáceo Superior \\
\hline Relevo local: & Colinas pouco amplas \\
\hline Erosão: & Não aparente \\
\hline Drenagem: & Bem drenado* \\
\hline Uso atual: & Pastagem \\
\hline Descrição e coletado por: & Melina Fushimi e João 0svaldo Rodrigues Nunes \\
\hline
\end{tabular}

*Esta condição refere-se ao momento da observação.

O perfil topográfico Oeste-Leste 2 (Figura 3) possui setores com solos profundos (Latossolos). Por outro lado, há solos rasos com o afloramento dos arenitos. Nas estradas vicinais, camadas de terra são depositadas sobre os solos, provenientes de outras áreas. O Ribeirão do Mandaguari, situado entre os municípios de Presidente Prudente, Indiana e Caiabú, está em estado de degradação, nele há o lançamento de esgoto e a formação de depósitos tecnogênicos, provocando modificações na mata ciliar, no curso d'água e acelerando, consequentemente, o processo de assoreamento. Nas planícies aluviais, locais favoráveis ao acúmulo de água durante certos períodos do ano, há solos com sinais de hidromorfismo (Planossolos Hidromórficos), cuja cor acinzentada está relacionada, sobretudo, à perda de óxido de ferro por redução. 


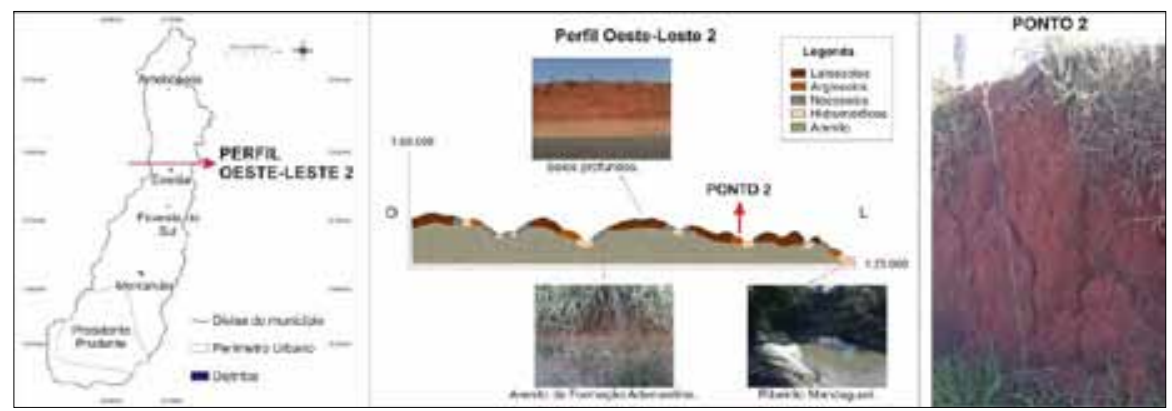

Figura 3 - Localização do perfil topográfico Oeste-Leste 2 e do Ponto 2 e perfil de Argissolo Vermelho

Ponto 2: Próximo ao Distrito de Eneida, foram observados solos com características de Argissolos Vermelhos (Figura 3) com um horizonte A alterado (Ap) pela pastagem e dois horizontes B texturais (Bt(1) e Bt(2)). Nas Tabelas 2 e 3, há a descrição geral do perfil e as características morfológicas realizadas no Ponto 2:

Tabela 2 - Descrição Geral do perfil de Argissolo Vermelho

\begin{tabular}{l|l}
\hline Data: & $15 / 8 / 2009$ \\
\hline Identificação: & Argissolo Vermelho \\
\hline Localização, Município, Estado e & $\begin{array}{l}\text { Próximo ao Distrito de Eneida, Presidente Prudente, } \\
\text { São Paulo, } 21^{\circ} 55^{\prime} 37,8^{\prime \prime} \text { S e } 51^{\circ} 18^{\prime} 00,2^{\prime \prime} \mathrm{W}\end{array}$ \\
\hline Coordenadas: & Média vertente com declividades entre 10 a 20\% \\
\hline Situação e declividade: & Floresta Tropical Subperenifólia e gramínea \\
\hline Cobertura vegetal primária e atual: & $398 \mathrm{~m}$ \\
\hline Altitude: & Arenito da Formação Adamantina \\
\hline Litologia e Formação Geológica: & Cretáceo Superior \\
\hline Cronologia: & Colinas pouco amplas \\
\hline Relevo local: & Não aparente \\
\hline Erosão: & Bem drenado* \\
\hline Drenagem: & Pastagem e agricultura \\
\hline Uso atual: & Melina Fushimi e João Osvaldo Rodrigues Nunes \\
\hline Descrição e coletado por: &
\end{tabular}

*Esta condição refere-se ao momento da observação. 
Tabela 3 - Características morfológicas e dados referentes à análise textural das amostras do perfil de Argissolo Vermelho (Ponto 2) coletadas em campo

\begin{tabular}{|c|c|c|c|c|c|}
\hline \multicolumn{6}{|c|}{ Classe de Solo: Argissolo Vermelho (Formação Adamantina) } \\
\hline \multicolumn{3}{|c|}{ Horizontes } & Ap & $\mathrm{Bt}(1)$ & $\mathrm{Bt}(2)$ \\
\hline \multicolumn{3}{|c|}{ Profundidade $(\mathrm{cm})$} & $0-32$ & $32-92$ & $92-150+$ \\
\hline \multicolumn{3}{|c|}{$\begin{array}{l}\text { Características } \\
\text { morfológicas }\end{array}$} & $\begin{array}{l}\text { Vermelho (5YR } \\
4 / 6)^{*} ; \text { transição } \\
\text { gradual; não } \\
\text { plástica; blocos } \\
\text { granulares e } \\
\text { em grumos; } \\
\text { muito porosos; } \\
\text { consistência } \\
\text { em solo seco: } \\
\text { ligeiramente } \\
\text { dura; em solo } \\
\text { úmido: firme. }\end{array}$ & $\begin{array}{l}\text { Vermelho (2,5YR } \\
\text { 4/6) }{ }^{*} \text {; transição } \\
\text { gradual; ligeiramente } \\
\text { plástica; blocos } \\
\text { angulares e } \\
\text { subangulares; } \\
\text { poros comuns; } \\
\text { cerosidade grau de } \\
\text { desenvolvimento: } \\
\text { forte, quantidade: } \\
\text { abundante; } \\
\text { consistência em solo } \\
\text { seco: dura; em solo } \\
\text { úmido: firme. }\end{array}$ & $\begin{array}{l}\text { Vermelho (2,5YR } \\
\text { 4/8)*; transição } \\
\text { gradual; ligeiramente } \\
\text { plástica; blocos } \\
\text { angulares e } \\
\text { subangulares; } \\
\text { poros comuns; } \\
\text { cerosidade grau de } \\
\text { desenvolvimento: } \\
\text { forte, quantidade: } \\
\text { abundante; } \\
\text { consistência em solo } \\
\text { seco: dura; em solo } \\
\text { úmido: solta. }\end{array}$ \\
\hline \multirow{4}{*}{$\begin{array}{l}\text { Análise } \\
\text { textural }\end{array}$} & Areia & \multirow{3}{*}{$\mathrm{g} / \mathrm{kg}^{-1}$} & 743,90 & 497,80 & 601,00 \\
\hline & Argila & & 176,00 & 412,00 & 311,00 \\
\hline & Silte & & 80,10 & 90,20 & 88,00 \\
\hline & \multicolumn{2}{|c|}{ Classe Textural } & Franco Arenosa & Argila Arenosa & $\begin{array}{l}\text { Franco Argilo } \\
\text { Arenosa }\end{array}$ \\
\hline
\end{tabular}

*As cores foram classificadas segundo a Carta de Munsell (2000) nas amostras secas.

Amostras de cada horizonte foram coletadas e submetidas à análise textural de acordo com o Manual de Métodos de Análise de Solos (Embrapa, 1997), utilizando o método da pipeta. Segundo Perusi (1997, p. 8), "a análise granulométrica ou textural é um importante elemento que deve complementar um "mosaico" de informações acerca dum determinado solo para que conclusões equivocadas sejam evitadas".

Mediante a análise textural (Tabela 3), verificou-se que a quantidade de areia diminui expressivamente no horizonte Bt(1) em comparação aos horizontes Ap e Bt(2). O horizonte Bt(1) apresenta acúmulo de argila, característico de um horizonte B textural, conferindo cerosidade forte em quantidade abundante, perceptível pelo aspecto lustroso e brilho graxo (Embrapa, 1999, p. 25).

Posteriormente, os resultados foram transpostos para o Diagrama Textural proposto pelo United States Department of Agriculture (U.S.D.A.), 
cuja classe textural dos horizontes Ap, Bt(1) e Bt(2) foram categorizadas respectivamente em "Franco Arenosa", "Argila Arenosa" e "Franco Argilo Arenosa”.

Percorrendo o perfil topográfico Oeste-Leste 3 (Figura 4), localizado ao norte de Presidente Prudente, próximo ao Distrito de Ameliópolis, observou-se que o setor oeste apresenta topos menos extensos com declividades que variam entre 6 a 20\%, solos rasos e afloramento dos arenitos. A morfologia das vertentes é, em sua maioria, retilínea com extenso comprimento de rampa, cobertura vegetal atual de gramínea e uso da terra pela pastagem. Em alguns pontos, as vertentes estão em situação de degradação e as planícies aluviais extensas com o predomínio da vegetação de taboa, indicativo de área de várzea. Já a leste, o mesmo perfil topográfico apresenta, de modo geral, colinas amplas suavemente onduladas, declive suave entre 0 a 10\%, favorecendo o cultivo da cana-de-açúcar em todas as épocas do ano.

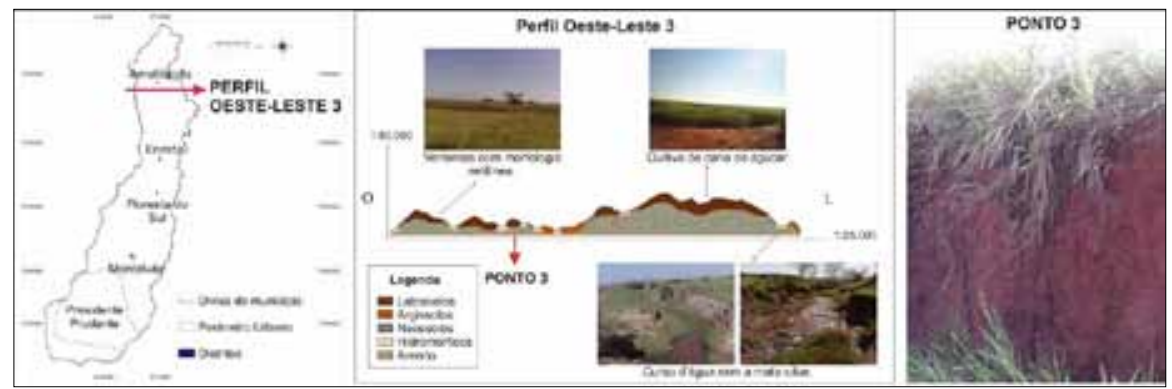

Figura 4 - Localização do perfil topográfico Oeste-Leste 3 e do Ponto 3 e perfil de Latossolo Vermelho

Ponto 3: Foram identificados solos profundos (Figura 4) com três horizontes (um horizonte raso Ap alterado especialmente pela pastagem e dois horizontes $\mathrm{B}$ latossólicos em avançado estágio de intemperização denominados $\mathrm{Bw}(1)$ e $\mathrm{Bw}(2))$. Analisando as características morfológicas dos horizontes subsuperficiais (Bw(1) e Bw(2)) (Tabela 5), nota-se que são muito porosos e há diferenciação pouco nítida entre eles (transição difusa), atributos de horizontes B latossólicos. 
Tabela 4 - Descrição Geral do perfil de Latossolo Vermelho

\begin{tabular}{l|l}
\hline Data: & $30 / 4 / 2010$ \\
\hline Identificação: & Latossolo Vermelho \\
\hline Localização, Município, Estado e & $\begin{array}{l}\text { Próximo ao Distrito de Ameliópolis, Presidente } \\
\text { Prudente, São Paulo, } 21^{\circ} 54^{\prime} 36,0^{\prime \prime} \text { e e } 51^{\circ} 19^{\prime} 12,0^{\prime \prime} \mathrm{W}\end{array}$ \\
\hline Coordenadas: & $\begin{array}{l}\text { Topo suavemente ondulado de colina com } \\
\text { declividades entre } 5 \text { a10\% }\end{array}$ \\
\hline Situação e declividade: & Floresta Tropical Subperenifólia e gramínea \\
\hline Cobertura vegetal primária e atual: & $403 \mathrm{~m}$ \\
\hline Altitude: & Arenito da Formação Adamantina \\
\hline Litologia e Formação Geológica: & Cretáceo Superior \\
\hline Cronologia: & Colinas com topos suavemente ondulados \\
\hline Relevo local: & Sulcos \\
\hline Erosão: & Bem drenado* \\
\hline Drenagem: & Pastagem e cultivo de cana de açúcar \\
\hline Uso atual: & Melina Fushimi e João Osvaldo Rodrigues Nunes \\
\hline Descrição e coletado por: &
\end{tabular}

*Esta condição refere-se ao momento da observação.

Tabela 5 - Características morfológicas e dados referentes à análise textural das amostras do perfil de Latossolo Vermelho (Ponto 3) coletadas em campo

Classe de Solo: Latossolo Vermelho (Formação Adamantina)

\begin{tabular}{|c|c|c|c|c|c|}
\hline \multicolumn{3}{|c|}{ Horizontes } & Ap & $\mathrm{Bw}(1)$ & $\mathrm{Bw}(2)$ \\
\hline \multicolumn{3}{|c|}{ Profundidade $(\mathrm{cm})$} & $0-10$ & $10-80$ & $80-150+$ \\
\hline \multicolumn{3}{|c|}{$\begin{array}{l}\text { Características } \\
\text { morfológicas }\end{array}$} & $\begin{array}{l}\text { Vermelho } \\
(2.5 Y R \text { 4/8); } \\
\text { transição gradual; } \\
\text { ligeiramente } \\
\text { plástica; blocos } \\
\text { granulares e } \\
\text { em grumos; } \\
\text { muito porosos; } \\
\text { consistência } \\
\text { em solo seco: } \\
\text { ligeiramente dura; } \\
\text { em solo úmido: } \\
\text { firme. }\end{array}$ & $\begin{array}{l}\text { Vermelho (10R } \\
\text { 3/6)*; transição } \\
\text { difusa; ligeiramente } \\
\text { plástica; blocos } \\
\text { angulares e } \\
\text { subangulares; } \\
\text { muito porosos; } \\
\text { consistência } \\
\text { em solo seco: } \\
\text { ligeiramente dura; } \\
\text { em solo úmido: } \\
\text { firme. }\end{array}$ & $\begin{array}{l}\text { Vermelho (10R } \\
4 / 8)^{*} ; \text { transição } \\
\text { difusa; plástica; } \\
\text { blocos angulares } \\
\text { e subangulares; } \\
\text { muito porosos; } \\
\text { consistência em } \\
\text { solo seco: solta; em } \\
\text { solo úmido: firme. }\end{array}$ \\
\hline \multirow{4}{*}{$\begin{array}{l}\text { Análise } \\
\text { textural }\end{array}$} & Areia & \multirow{3}{*}{$\mathrm{g} / \mathrm{kg}^{-1}$} & 710,72 & 584,03 & 647,73 \\
\hline & Argila & & 169,00 & 319,00 & 242,60 \\
\hline & Silte & & 120,28 & 96,96 & 109,59 \\
\hline & \multicolumn{2}{|c|}{ Classe Textural } & Franco Arenosa & $\begin{array}{l}\text { Franco Argilo } \\
\text { Arenosa }\end{array}$ & $\begin{array}{l}\text { Franco Argilo } \\
\text { Arenosa }\end{array}$ \\
\hline
\end{tabular}

*As cores foram classificadas segundo a Carta de Munsell (2000) nas amostras secas. 
Diante dos resultados obtidos, por meio da análise textural (Tabela 5) e das observações acerca da paisagem do Ponto 3, os solos dessa área são caracterizados como Latossolos Vermelhos. Em todos os horizontes, os teores de silte estão abaixo de $200 \mathrm{~g} / \mathrm{kg}^{-1}$, valores típicos de Latossolos. No entanto, a quantidade de argila, apesar de não dobrar do horizonte superficial (Ap) para o horizonte posterior (Bw(1)), aumenta consideravelmente e a classe textural dos horizontes Bw(1) e Bw(2) é categorizada como "Franco Argilo Arenosa". Além disso, relacionando o relevo ondulado com declividades altas (para a região de Presidente Prudente) pressupõe-se que estes Latossolos estão em fase de transição para Argissolos.

\section{Considerações finais}

O uso atual da terra no município de Presidente Prudente-SP, composto predominantemente pela pastagem com a ocorrência de queimadas em algumas épocas do ano, influencia no desenvolvimento do horizonte A antrópico, com vestígios de queimada até mesmo nos horizontes subsuperficiais. No setor norte, próximo ao Distrito de Ameliópolis, predominam as lavouras de cana de açúcar, paisagem diferenciada do resto do município. De modo geral, a cobertura vegetal original foi removida e atualmente há o predomínio de gramínea.

As manchas de Latossolos Vermelhos apresentam-se nos topos suavemente ondulados dos compartimentos das colinas convexizadas (sobretudo nas colinas mais amplas) e vertentes com extenso comprimento de rampa e morfologia retilínea. Em alguns setores dos topos, existe o afloramento dos arenitos da Formação Adamantina. As altitudes variam entre 400 a $480 \mathrm{~m}$ e as declividades médias de 0 a $10 \%$.

Os Argissolos Vermelhos ocorrem nas colinas de topos menos extensos e no domínio das vertentes convexo-côncavas e retilíneas (340 a $400 \mathrm{~m}$ ), declividades aproximadas entre 5 a 20\%. Os Neossolos Regolíticos predominam em vertentes íngremes com declividades acima de $20 \%$, cujo afloramento dos arenitos da Formação Adamantina é frequente.

Já nos fundos de vales (290 a 340 m), em especial com morfologia em berço, identificou-se a presença de solos hidromórficos (Planossolos e Gleissolos), mas também depósitos sedimentares de origem antrópica, ou seja, depósitos tecnogênicos. Nesses locais, as declividades médias variam entre 0 a $5 \%$. 


\section{Notas}

1. SPRING é marca registrada pelo INPE.

2. CorelDRAW é marca registrada pela Corel Corporation.

\section{Referências}

AB'SABER A. N. Os baixos chapadões do Oeste Paulista. Geomorfologia, São Paulo, n. 17, p. 1-8, 1969.

EMPRESA BRASILEIRA DE PESQUISA AGROPECUÁRIA (Embrapa). Manual de Métodos de Análise de Solos. Rio de Janeiro, 1997. 212p.

EMPRESA BRASILEIRA DE PESQUISA AGROPECUÁRIA (Embrapa). Sistema Brasileiro de Classificação de Solos. Brasília-DF: Serviço de Produção de Informação (SPI), 1999.

INSTITUTO BRASILEIRO DE GEOGRAFIA E ESTATÍSTICA (IBGE), 2010. Disponível em: <http://www.ibge.gov.br>. Acesso em: 10 fev. 2011.

LEPSCH, I. F. Formação e Conservação dos Solos. São Paulo: Oficina de Textos, 2002. 178p.

MORAES REGO, L. F. de. Notas sobre a geomorfologia de São Paulo e sua gênesis. São Paulo: Inst. Astron. Geofísico, 1932. 43p.

MUNSELL. Soil Color Charts. New Windsor, NY: Kollmorgen Instruments, Macbeth Division, 2000.

OLIVEIRA, J. B. de. Solos do Estado de São Paulo: descrição das classes registradas no mapa pedológico. Campinas: Instituto Agronômico, 1999. 112p.

PERUSI, M. C. Dispersão das argilas de alguns solos do Oeste do Estado de São Paulo. Monografia (Bacharelado em Geografia) - Faculdade de Ciências e Tecnologia, Universidade Estadual Paulista, Presidente Prudente, 1997. 33p.

ROSS, J. L. S.; MOROZ, I. C. Mapa geomorfológico do Estado de São Paulo. Rev. do Departamento de Geografia, São Paulo, n. 10, 1996.

SOIL SURVEY STAFF. Soil survey manual. United States: Department of Agriculture, 1951.

Melina Fushimi - Licenciada e Bacharel em Geografia pela Universidade Estadual Paulista. Mestranda em Geografia da mesma Universidade.

João Osvaldo Rodrigues Nunes - Doutor em Geografia pela Universidade Estadual Paulista e professor adjunto da mesma Universidade. 